\title{
Didactics of Mathematics Profile of Engineering Students: A Case Study in a Multimedia Engineering Degree
}

\author{
Maria Luisa Pertegal-Felices \\ San Vicente del Raspeig, University of Alicante, 03690 Alicante, Spain; ml.pertegal@ua.es
}

Received: 14 January 2020; Accepted: 6 February 2020; Published: 7 February 2020

\begin{abstract}
Multimedia engineers develop digital content in a wide range of fields that require them to acquire skills in the development of web solutions for those fields. In this study, we evaluated the level of didactic knowledge of mathematics that Multimedia Engineering degree students possess. The aim was to determine whether they are prepared to conceive, design and develop educational multimedia tools for teaching mathematics to primary school children. For this evaluation, the Didactic-Mathematical Knowledge and Elementary Algebraic Reasoning (DMK/EAR) test was carried out on a sample of 50 students in the second year of a Multimedia Engineering Degree. The results were compared with those of teacher training students who receive specific training in mathematics didactics. The study shows that, for most of the variables analysed, the Multimedia student scored better or comparatively equal to the teaching trainee. In conclusion, students of Multimedia Engineering have a solid foundation in the didactics of mathematics, although some deficiencies have been detected in the cognitive dimension and the content in structures, which indicate that they would need to complete their training in these areas.
\end{abstract}

Keywords: didactics of mathematics; mathematics teaching; specific competences; ICT engineering

\section{Introduction}

Information and communication technologies (ICT) engineering establishes the basis for solutions that are applied in various fields. Often, the areas to which the technology is directed are of a very different nature to the areas of these technologies. For this reason, this type of engineer is required to have a solid base of transversal skills that help to formalise, design and develop these solutions in different areas. In fact, in the professional field of engineering graduates, the Career Space project [1] was developed with the support of the European Commission. This project provides a set of guidelines and recommendations as a basis for curriculum development, analysing 100 ICT curricula from nine European countries that were followed by various programmes [2,3]. The project specifies that "ICT graduates need to learn to work in teams and acquire strong personal skills, such as problem-solving abilities, an awareness of the need for lifelong learning, the ability to fully understand the needs of clients and project partners, and an awareness of cultural differences when operating in a global context. Therefore, in the development of a product, the engineer must participate in an interdisciplinary team where managing the common basic concepts and competences is crucial for the success of the project.

In recent years, in parallel with the development of web technologies, we have seen the huge production of ICT tools for educational purposes [4,5]. ICT professionals and educators often collaborate in the development of these products. On the one hand, the educator directs the pedagogical purpose of the tool, while the engineer adapts this objective to the available technological elements and develops a means of interaction that is accessible to the target audience. From this collaboration emerge synergies that enrich the final product while providing a solid basis for learning $[6,7]$. 
In this scenario of interdisciplinary work, the communication of ideas from different fields is crucial and is even more effective when the engineer has more educational knowledge and the educator has more technological knowledge. Although the skill profiles that are assumed for the ICT engineer include aspects of transversality and generality that are necessary to start an interdisciplinary work with a guarantee of success, few studies have revealed the didactic profile of ICT engineers in order to check whether their training is sufficient to tackle this type of interdisciplinary work more effectively. Experiences in the field of teacher training have been documented. In the case of mathematics education, several studies show the knowledge and skills needed to achieve effective teaching of students [8-11]. On the other hand, ICT engineers possess, in their catalogue of competences, knowledge and skills specific to mathematics that allow them to understand, abstract and model solutions in the field of technology, but their competences do not include those linked to the didactics of mathematics.

Several studies have been conducted to measure the level of competence of university students in mathematics didactics [12-14]. According to Godino et al. [12], promoting algebraic thinking in primary school students requires implementing specific training actions for teachers. Consequently, in this study, a mathematical reasoning questionnaire was presented with the objective of evaluating the didactic-mathematical knowledge and elementary algebraic reasoning among teachers' students. This questionnaire was applied to 91 students belonging to various Spanish universities.

In accordance with the conclusions of the previous study, the aim of this research was to find out the level of mathematics teaching skills that multimedia engineers possess. An analysis of this type of competence will allow us to understand the starting level that this type of engineer has in order to successfully start an interdisciplinary work with educators to develop web tools focused on the learning of mathematics by primary school students.

\section{Method}

\subsection{Description of the Context and Participants}

Multimedia Engineering is a new academic profile that provides training based on the fundamentals of engineering, supported, like other engineering studies, in information and communication technologies, but characterised by the use of multimedia resources as a backbone. It is, therefore, an engineering discipline related to other engineering fields, such as computer science, telecommunications or image and sound. This is a relatively new degree and it is borne from the current needs of a society that is increasingly dependent on new technologies. The degree has a widely interdisciplinary profile, and the professional opportunities for its graduates are very diverse: web applications, mobile applications, video games, animation projects, marketing and advertising, content management (press, radio, television, etc.). Given its cross-cutting nature, its areas of application are also very heterogeneous: business, industry, education, leisure, health, defense, and so on. Specifically, this study was conducted with students studying a Multimedia Engineering degree at the University of Alicante.

In this work, we propose to determine if multimedia students have the appropriate knowledge to develop mathematical teaching tools. Therefore, it is convenient to analyse the mathematical competences developed within the degree. Table 1 shows that, within the degree itself, there are two specific basic skills associated with mathematical knowledge ( $\mathrm{C} 1$ and $\mathrm{C} 2$ in Table 1$)$. These competences are directly developed in the curriculum in the three core first year subjects (see Table 2). 
Table 1. Core competences of students studying a Multimedia Engineering degree at the University of Alicante.

\begin{tabular}{ll}
\hline Identifier & \multicolumn{1}{c}{ Competence } \\
\hline C1 & $\begin{array}{l}\text { Solving mathematical problems that may arise in multimedia engineering by applying } \\
\text { knowledge of algebra, geometry, differential and integral calculus, numerical methods, statistics } \\
\text { and optimisation. }\end{array}$ \\
\hline C2 & $\begin{array}{l}\text { Understanding and mastering the basic concepts of discrete mathematics, logic and its } \\
\text { application to the automatic processing of information by means of computer systems and to the } \\
\text { resolution of problems typical of engineering. }\end{array}$ \\
\hline C3 & $\begin{array}{l}\text { Knowledge and understanding of the basics of computer use and programming, algorithmic } \\
\text { and computational complexity. }\end{array}$ \\
\hline C4 & $\begin{array}{l}\text { Knowledge and understanding of the structure, operation and interconnection of multimedia } \\
\text { computer systems. }\end{array}$ \\
\hline C5 & $\begin{array}{l}\text { Understanding and mastering the basic fundamentals of physics and its application to } \\
\text { computing and signal processing for the resolution of problems typical of multimedia } \\
\text { engineering. }\end{array}$ \\
\hline C7 & $\begin{array}{l}\text { Knowledge and understanding of the concept of the company, its institutional and legal } \\
\text { framework, as well as its organisation and management. }\end{array}$ \\
\hline C8 & $\begin{array}{l}\text { Knowledge of the fundamentals of graphic expression and design, applying them to multimedia } \\
\text { contents and developing the capacity for spatial vision. }\end{array}$ \\
\hline
\end{tabular}

Table 2. Subjects related to mathematical competences.

\begin{tabular}{clccc}
\hline Year & Type & Credits $^{*}$ & Subject & Competence \\
\hline 1 & Core & 6 & Matemathics I & B2 \\
1 & Core & 6 & Matemathics II & B1 \\
1 & Core & 6 & Statistics & B1 \\
\hline \multicolumn{5}{c}{ * one credit is equivalent to 25 h of student work. }
\end{tabular}

It should be noted that most students admitted to the degree had previously studied five mathematics subjects in high school (one each year).

The study was carried out on a sample of students from the Multimedia Engineering degree at the University of Alicante, specifically with second year students for the 2017/2018 academic year. The sample consisted of 50 students with a gender distribution of $84 \%$ men and $16 \%$ women.

\subsection{Instruments}

The test used in this research was the Didactic-Mathematical Knowledge and Elementary Algebraic Reasoning test (DMK/EAR) proposed in [12]. This test is based on the elementary algebraic reasoning model (EAR) [10] and on the didactic-mathematical knowledge model (DMK) previously proposed by the same author [15]. This instrument applies two types of theoretical tools: those related to the conceptualisation of elementary algebraic reasoning and those related to the model of didactic-mathematical knowledge.

This instrument provides information about two dimensions. On one hand, the algebraic content dimension has three categories: the "CEST" structure dimension, which establishes equivalence relationships; the "CFUN" function dimension, which represents the use of arithmetic patterns, geometric patterns, functions, etc., and the "CMOD" modelling category, which deals with context problems solved by the equation or relationship approach. On the other hand, the dimension of didactic content presents four categories: the epistemic component "DEPI" that deals with the recognition of 
algebraic objects and processes; the cognitive component "DCOG" that represents personal meanings of the students on elementary algebra and learning conflicts; the instructional component "DINS" that deals with the resources for teaching algebra and its adaptation to the school curriculum and, finally, the algebraic component "DALG" that includes the process of the interpretation of algebraic expressions and modelling.

The instrument consists of 10 questions comprising various types of mathematical problems, with several sections asking for both the solution to the problem and the primary school students' interpretation of the same statement and its response options, as well as proposals for improving or reinterpreting the questions. For the correction of each question, three levels of response are established: correct ( 2 points), partially correct ( 1 point) and incorrect ( 0 points). In each question and section, different categories and dimensions are evaluated, according to Table 3.

Table 3. List of questions and sections of the didactic-mathematical knowledge/elementary algebraic reasoning $(\mathrm{DMK} / \mathrm{EAR})$ test and the dimensions involved.

\begin{tabular}{|c|c|c|c|c|c|c|c|}
\hline \multirow[b]{2}{*}{ Questions } & \multicolumn{4}{|c|}{ Didactic } & \multicolumn{3}{|c|}{ Cognitive } \\
\hline & DEPI & DCOG & DINS & DALG & CEST & CFUN & CMOD \\
\hline 1a. Equality of arithmetic result. Explanation & & $x$ & & & $X$ & & \\
\hline 1b. Equality of arithmetic result. Interpretation & & $x$ & & & $x$ & & \\
\hline 2a. Equality of equivalence. Explanation & & $x$ & & & $x$ & & \\
\hline 2b. Equality of equivalence. Properties & $x$ & & & & $x$ & & \\
\hline 3a. Add three numbers. Generalisation & & & & $X$ & $X$ & & \\
\hline 3b. Add three numbers. Type of justification & & $x$ & & & $X$ & & \\
\hline 4a. Incomplete sum. Resolution and explanation & & & & $X$ & $X$ & & \\
\hline 4b. Incomplete sum. Algebraic solution & $x$ & & & & $x$ & & \\
\hline 4c. Incomplete sum. School solution & & $x$ & & & $x$ & & \\
\hline 5a. Hexagonal pattern. Two terms & & & & $\mathrm{X}$ & & $x$ & \\
\hline 5b. Hexagonal pattern. Algebraic generalisation & & & $x$ & & & $x$ & \\
\hline 5c. Hexagonal pattern. Types of algebraic objects & $x$ & & & & & $x$ & \\
\hline 6a. Square pattern. General solution & & & & $X$ & & $x$ & \\
\hline 6b. Square pattern. Possible techniques & $X$ & & & & & $x$ & \\
\hline 7a. Cost of food. Resolution & & & & $X$ & $X$ & & \\
\hline 7b. Cost of food. Arithmetic solution & $x$ & & & & $x$ & & \\
\hline 7c. Cost of food. Arithmetic solution & $\mathrm{X}$ & & & & $x$ & & \\
\hline 8a. Interpretation of expressions & & & & $X$ & & $x$ & \\
\hline 8b. Problems statement & & & $x$ & & $X$ & $x$ & $x$ \\
\hline 9a. Graphical functions. Justification & & & & $X$ & & $x$ & $x$ \\
\hline 9b. Graphical functions. Object recognition & $x$ & & & & & & $x$ \\
\hline 9c. Graphical functions. Curriculum & & & $x$ & & & & $x$ \\
\hline 10a. Linear functions. Statements & & & $x$ & & & $x$ & $x$ \\
\hline 10b. Linear functions. Algebra recognition & $x$ & & & $x$ & & $x$ & \\
\hline
\end{tabular}

In the results section, the level of each normalised variable in the (0-100) range is presented. The instrument was applied in a classroom during teaching hours and was administered for a maximum time of $2 \mathrm{~h}$.

\subsection{Procedure}

The DMK/EAR test was applied to a sample of 50 Multimedia Engineering degree students and was statistically compared with the results obtained from the sample of 91 Teacher Training Degree students cited in the Godino study [12]. The statistical procedure was done by comparing the test scores of both groups, using the $t$ statistic. The SPSS v.24 package was used to perform the statistical tests.

\section{Results}

The results obtained for each of the variables treated are shown below. The descriptions of the tests are shown in Table 4. 
Table 4. Descriptive of DMK/EAR test scores for both groups of students.

\begin{tabular}{cccccc}
\hline \multirow{2}{*}{ GROUP } & N & Mean & $\begin{array}{c}\text { Standard } \\
\text { Deviation }\end{array}$ & $\begin{array}{c}\text { Mean } \\
\text { Standard Error }\end{array}$ \\
\hline \multirow{2}{*}{ DCOG } & MULTIMEDIA & 50 & 33.22 & 13.57 & 1.92 \\
& TEACHER & 91 & 42.09 & 1.63 & 0.17 \\
DEPI & MULTIMEDIA & 50 & 24.59 & 8.64 & 1.22 \\
& TEACHER & 91 & 15.15 & 0.97 & 0.10 \\
DINS & MULTIMEDIA & 50 & 26.17 & 15.21 & 2.15 \\
& TEACHER & 91 & 22.12 & 1.55 & 0.16 \\
DALG & MULTIMEDIA & 50 & 60.57 & 9.53 & 1.34 \\
& TEACHER & 91 & 42.24 & 1.54 & 0.16 \\
CEST & MULTIMEDIA & 50 & 27.89 & 7.50 & 1.06 \\
& TEACHER & 91 & 36.06 & 1.06 & 0.11 \\
CMOD & MULTIMEDIA & 50 & 39.94 & 16.49 & 2.33 \\
& TEACHER & 91 & 36.13 & 1.82 & 0.19 \\
CFUN & MULTIMEDIA & 50 & 46.84 & 9.20 & 1.30 \\
& TEACHER & 91 & 24.08 & 1.00 & 0.10 \\
\hline
\end{tabular}

\subsection{Didactic Contents}

Table 5 shows the results of the $t$ test for each of the variables of the didactic profile.

Table 5. $t$ test for equality of means between scores for the DMK/EAR test learning content variables.

\begin{tabular}{ccccc}
\hline Variable & $\mathbf{t}$ & $\mathbf{d f}$ & Significance & Difference * \\
\hline DCOG & -4.60 & 49.78 & $0.000^{* *}$ & -8.87 \\
DEPI & 7.69 & 49.68 & $0.000^{* *}$ & 9.44 \\
DINS & 1.87 & 49.57 & 0.067 & 4.04 \\
DALG & 13.50 & 50.42 & $0.000^{* *}$ & 18.33
\end{tabular}

* the difference corresponds to the score of the Multimedia Engineering students with respect to the Teaching students. ${ }^{* *}$ significant at level 0.01 .

Firstly, with respect to the didactic profile, the students of Multimedia Engineering scored significantly above the Teaching students in the algebraic (+18.3 points on a scale of 100) and epistemic (+9.4 points) facets, scoring significantly below the average of the students of Teaching in the cognitive facet ( -8.9 points).

In the instructional facet, the Multimedia student scored slightly above the Teaching student $(+4.0$ points), however, statistical analysis showed that the difference could be due to chance. Figure 1 shows the scores obtained by both groups of students.

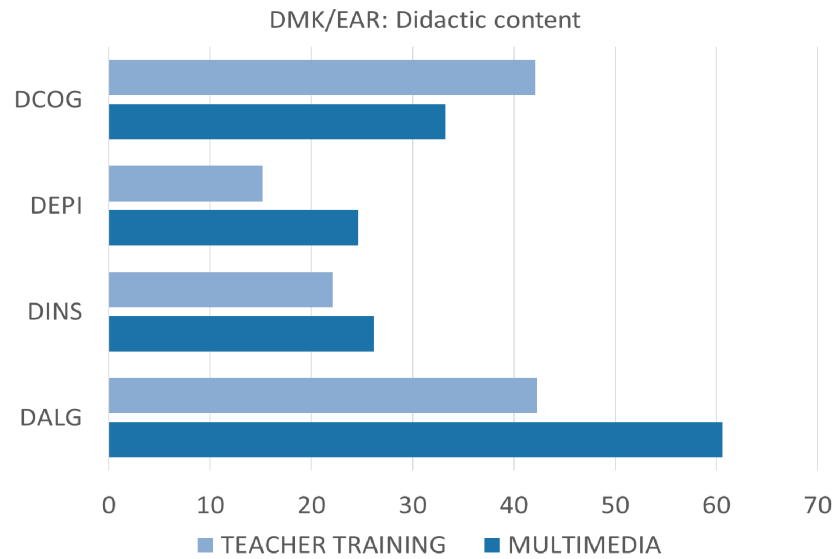

Figure 1. Didactic knowledge scores obtained by Multimedia and Teaching students. 


\subsection{Algebraic Contents}

Table 6 shows the results of the $t$ test for each of the variables of the algebraic profile.

Table 6. $t$-test for equality of means between scores for the DMK/EAR test algebraic content variables.

\begin{tabular}{ccccc}
\hline Variable & $\mathbf{t}$ & $\mathbf{d f}$ & Significance & Difference $^{*}$ \\
\hline CEST & -7.65 & 50.09 & $0.000^{* *}$ & -8.16 \\
CMOD & 1.63 & 49.66 & 0.110 & 3.81 \\
CFUN & 17.42 & 49.64 & $0.000^{* *}$ & 22.75 \\
\hline
\end{tabular}

* the difference corresponds to the score of the Multimedia Engineering students with respect to the Teaching students. ${ }^{* *}$ significant at level 0.01 .

Regarding the algebraic profile, the Multimedia Engineering students scored significantly better in functions (+22.8 points out of 100) but obtained significantly lower results than the Teaching students in structures ( -8.2 points out of 100). Regarding the last variable of this profile, modelling, the Multimedia student scored slightly higher than the Teaching student ( +3.8 points over 100$)$, but this difference was not statistically significant. Figure 2 shows the scores obtained by both groups of students.

DMK/EAR: Algebraic content

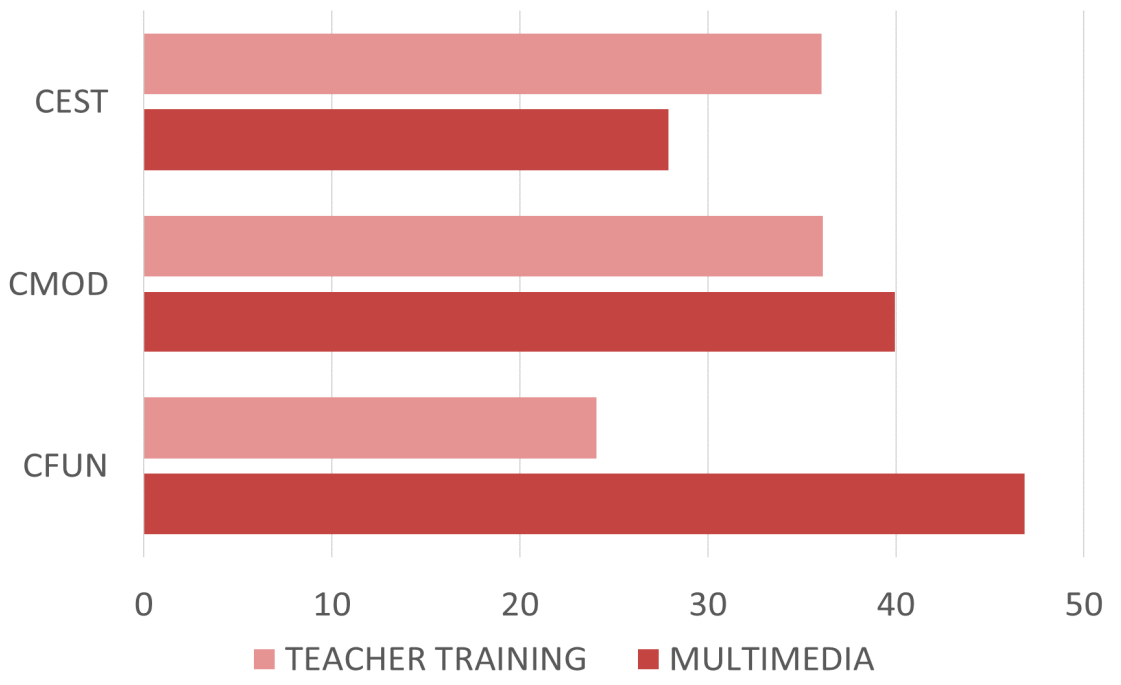

Figure 2. Algebraic knowledge scores obtained by Multimedia and Teaching students.

\section{Discussion and Conclusions}

Multimedia Engineering is a type of ICT engineering that prepares professionals to develop all kinds of digital content. It is a professional discipline that bases its success on the collaborative and interdisciplinary work that provide more usefulness to the developed tool; such is the case with the design of educational digital applications, where ICT engineers and educators collaborate closely with the aim of providing students with tools that make their learning easier. Although the skills profile of the ICT engineer is transversal enough to successfully address an interdisciplinary work, few studies have allowed us to know their didactic profile of mathematics in order to check if their training is enough to design digital content for mathematics teaching.

Part of the success in the development of a web application for teaching mathematics lies in the didactic knowledge of mathematics that these engineers possess. However, while the level of competence in didactics of mathematics has been evaluated for teacher training students in Spain, thanks to studies such as Godino's [12], a lack of this type of evaluation is observed in the field of ICT degrees, which does not allow us to know a priori what the level of knowledge of the engineers in this discipline is. 
In this research, the level of competences in didactics of mathematics that Multimedia Engineering students possess has been evaluated using the DMK/EAR test. Analysis of this type of competence has allowed us to understand the level of knowledge that this type of student has in order to successfully start an interdisciplinary work with educators. Although it seems clear that the specific competences in mathematics of Multimedia Engineering students have been sufficiently considered at the different educational levels, this study has focused on determining whether these can be transferred into didactic competences in mathematics, which are necessary for the creation of adequate pedagogical tools.

As a conclusion to this study, we can say that, in general, students of Multimedia Engineering have a solid base in terms of didactics of mathematics, since they were placed in levels equal or higher than students of Teaching who have received specific training in this regard. On the other hand, deficiencies have been detected in two of the seven variables analysed-cognitive didactics and content in structures-which indicate that they would need to complete their training in these areas.

One of the future lines of work of this research, once the didactic capacity of Multimedia Engineering students in the design of mathematical activities for children has been shown, is to put this design capacity into practice and measure the impact it has on the learning process of children. To this end, during this academic year, students in this discipline will design their own mathematical learning tools for children. Later, these web applications will be used by primary school children. The results of this future research will assess whether these applications increase children's mathematical performance and whether they do so to a greater or lesser extent than other strategies carried out by teachers themselves.

Conflicts of Interest: The author declares no conflict of interest.

\section{References}

1. Career Space Curriculum Development Guidelines. New ICT Curricula for the 21st Century: Designing Tomorrow's Education. Available online: http://www.cedefop.europa.eu/files/2204_en.pdf (accessed on 5 January 2020).

2. Casanovas, J.; Colom, J.M.; Morlán, I.; Pont, A.; Sancho, M.R. El libro blanco de la Ingeniería en Informática: El proyecto EICE. Actas Las X Jorn. Enseñ. Univ. Informática Jenui 2004, 1, 13-18.

3. Marín, S.L.T.; Martínez Torres, R.; García, F.J.B.; Vázquez, S.G.; Vargas, E.; Ayala, V.G. Planning a Master's Level Curriculum According to Career Space Recommendations Using Concept Mapping Techniques. Int. J. Technol. Des. Educ. 2006, 16, 237-252. [CrossRef]

4. Conole, G.; Alevizou, P. A Literature Review of the Use of Web 2.0 Tools in Higher Education; HEA Academy: York, UK, 2010.

5. Murphy, K.L.; Cifuentes, L. Using Web tools, collaborating, and learning online. Distance Educ. 2001, 22, 285-305. [CrossRef]

6. Marcos-Jorquera, D.; Pertegal-Felices, M.L.; Jimeno-Morenilla, A.; Gilar-Corbi, R. An interdisciplinary practical for multimedia engineering students. IEEE Trans. Educ. 2017, 60, 8-15. [CrossRef]

7. Zeidmane, A.; Cernajeva, S. Interdisciplinary approach in engineering education. In Proceedings of the Global Engineering Education Conference (EDUCON), Amman, Jordan, 4-6 April 2011; pp. 1096-1101.

8. Baumert, J.; Kunter, M.; Blum, W.; Brunner, M.; Voss, T.; Jordan, A.; Klusmann, U.; Krauss, S.; Neubrand, M.; Tsai, Y.-M. Teachers' Mathematical Knowledge, Cognitive Activation in the Classroom, and Student Progress. Am. Educ. Res. J. 2010, 47, 133-180. [CrossRef]

9. Boero, P.; Dapueto, C.; Parenti, L. Didactics of Mathematics and the Professional Knowledge of Teachers. In International Handbook of Mathematics Education; Kluwer International Handbooks of Education; Springer Nautre: Dordrecht, The Netherlands, 1996; Volume 4, pp. 1097-1121. ISBN 978-94-010-7155-0.

10. Godino, J.D.; Aké, L.P.; Gonzato, M.; Wilhelmi, M.R. Niveles de algebrización de la actividad matemática escolar. Implicaciones para la formación de maestros. Enseñ. Las Cienc. Rev. Investig. Exp. Didácticas 2014, 32, 199-219. [CrossRef] 
11. Petrou, M.; Goulding, M. Conceptualising Teachers' Mathematical Knowledge in Teaching. In Mathematical Knowledge in Teaching; Mathematics Education Library; Springer Nautre: Dordrecht, The Netherlands, 2011; pp. 9-25. ISBN 978-90-481-9765-1.

12. Godino, J.D.; Aké, L.; Contreras, Á.; Estepa, A.; Fernandez, T.; Neto, T.; Wilhelmi, M.R.; Díaz, C.; Oliveras, M.L.; Lacasta, E. Diseño de un cuestionario para evaluar conocimientos didáctico-matemáticos sobre razonamiento algebraico elemental. Enseñ. Las Cienc. Rev. Investig. Exp. Didácticas 2015, 33, 127-150.

13. Heuvel-Panhuizen, M.; van den Becker, J. Towards a Didactic Model for Assessment Design in Mathematics Education. In Second International Handbook of Mathematics Education; Springer International Handbooks of Education; Springer Nautre: Dordrecht, The Netherlands, 2003; pp. 689-716. ISBN 978-94-010-3951-2.

14. Pino-Fan, L.R.; Assis, A.; Castro, W.F. Towards a Methodology for the Characterization of Teachers' Didactic-Mathematical Knowledge. Eurasia J. Math. Sci. Technol. Educ. 2015, 11, 1429-1456.

15. Godino, J.D. Categorías de análisis de los conocimientos del profesor de matemáticas. UNIÓN Rev. Iberoam. Educ. Matemática 2009, 20, 13-31.

(C) 2020 by the author. Licensee MDPI, Basel, Switzerland. This article is an open access article distributed under the terms and conditions of the Creative Commons Attribution (CC BY) license (http://creativecommons.org/licenses/by/4.0/). 